J Mol Neurosci. 2011 November ; 45(3): 438-444. doi:10.1007/s12031-011-9566-7.

\title{
Are Tangles as Toxic as They Look?
}

\author{
Tara L. Spires-Jones \\ Massachusetts General Hospital, Harvard Medical School, 114 16th Street, Charlestown, MA \\ 02129, USA
}

\author{
Katherine J. Kopeikina \\ Massachusetts General Hospital, Harvard Medical School, 114 16th Street, Charlestown, MA \\ 02129, USA \\ Department of Anatomy and Neurobiology, Boston University School of Medicine, 72 East \\ Concord Street (L 1004), Boston, MA 02118, USA \\ Robert M. Koffie \\ Massachusetts General Hospital, Harvard Medical School, 114 16th Street, Charlestown, MA \\ 02129, USA
}

\author{
Alix de Calignon \\ Department of Physiology, Anatomy, and Genetics, University of Oxford, Parks Road, Oxford \\ OX1 3PT, UK \\ Bradley T. Hyman \\ Massachusetts General Hospital, Harvard Medical School, 114 16th Street, Charlestown, MA \\ 02129, USA
}

\begin{abstract}
Neurofibrillary tangles are intracellular accumulations of hyperphosphorylated and misfolded tau protein characteristic of Alzheimer's disease and other tauopathies. Classic cross-sectional studies of Alzheimer patient brains showed associations of tangle accumulation with neuronal loss, synapse loss, and dementia, which led to the supposition that tangles are toxic to neurons. More recent advances in imaging techniques and mouse models have allowed the direct exploration of the question of toxicity of aggregated versus soluble tau and have surprisingly challenged the view of tangles as toxic species in the brain. Here, we review these recent experiments on the nature of the toxicity of tau with particular emphasis on our experiments imaging tangles in the intact brain through a cranial window, which allows observation of tangle formation and longitudinal imaging of the fate of tangle-bearing neurons. Neurofibrillary tangles (NFT) were first described in 1906 by Alois Alzheimer based on Bielschowsky silver staining of the brain of his demented patient Auguste D (Alzheimer 1907; Goedert and Spillantini 2006). These intraneuronal aggregates have subsequently been found to be composed primarily of hyperphosphorylated tau protein and are definitive pathological lesions not only in Alzheimer's disease but also in a class of neurodegenerative tauopathies (Goedert et al. 1988; Spires-Jones et al. 2009). NFT pathology in Alzheimer's disease (AD) correlates closely with cognitive decline and synapse and neuronal loss (Braak and Braak 1997; Bretteville and Planel 2008; Congdon and Duff 2008; Mocanu et al. 2008b; Spires-Jones et al. 2009). As a result, NFT have long been considered indicative of impending neuronal cell death. More recent evidence, however, opposes this classical view. Here
\end{abstract}

(C) Springer Science+Business Media, LLC 2011

tspires@partners.org .

bhyman@partners.org 
we review evidence addressing the question of whether NFT cause structural or functional neuronal damage.

\section{Keywords}

Tau; Alzheimer; Neurofibrillary tangle; Neurodegeneration

\section{Classical View of Tangles as Toxic}

Tau is a microtubule-associated protein (Goedert and Spillantini 2006; Selkoe 2001)

primarily expressed in the central nervous system. The tau protein has over 80 phosphorylation sites and is tightly regulated by protein kinases and phosphatases

(Bretteville and Planel 2008; Hyman et al. 2005; Spires-Jones et al. 2009). During disease pathogenesis, normal tau becomes hyperphosphorylated, causing it to fall off the microtubules and be relocated to the somatodendritic compartment (Bramblett et al. 1993; Stoothoff and Johnson 2005). Here it is subjected to further phosphorylation and conformational change, which leads to the formation of paired helical and straight filaments of abnormal tau. These filamentous or fibrillar forms of tau aggregate into mature NFT (Kuret et al. 2005).

It is indisputable that tau dysfunction can lead to neurodegeneration. While neurofibrillary tau pathology in $\mathrm{AD}$ may be downstream of amyloid beta induced stressors, mutations in tau can lead to autosomal dominant frontotemporal dementia and Parkinsonism linked to chromosome 17 (Hutton 2001; Hutton et al. 1998). Overexpressing human wild-type or dementia-associated mutant forms of tau also lead to neuronal death in cell culture, drosophila systems, and in several transgenic mouse lines (Bulic et al. 2007; Hutton et al. 2001; Khlistunova et al. 2006; Shulman and Feany 2003; Spires and Hyman 2005; Wittmann et al. 2001). While the mechanism of tau causing neuronal dysfunction and death remains unclear, there is strong evidence that hyperphosphorylation, mislocalization to the somatodendritic compartment, and aggregation all contribute.

Aggregation of tau into mature, silver-positive NFT has been thought to contribute to neuronal loss in AD based on the close correlations between NFT pathology, both in terms of location and number, and degree of AD severity and cognitive decline (Arriagada et al. 1992; Giannakopoulos et al. 2003; Gomez-Isla et al. 1996). It is important to note, however, that neuronal loss exceeds NFT number by at least one order of magnitude and the two become completely dissociated in several brain regions (Gomez-Isla et al. 1997;Terry 2000; van de Nes et al. 2008; Vogt et al. 1998). In many of the mouse models that overexpress FTD-associated mutant tau, NFT form in some of the same regions that undergo neuronal loss (Allen et al. 2002; Andorferet al. 2005; SantaCruz et al. 2005; Spires et al. 2006;Zehr et al. 2004), but it is unclear from these studies whether NFT play a role in cell loss. In fact, markers of cell death were not found in NFT bearing neurons in htau mice (Andorfer et al. 2005), indicating that cell death occurs independently of NFT. Mandelkow et al. have shown that in cultured cells, expression of an aggregate-prone tau construct is associated with cell death (Khlistunova et al. 2006; Wang et al. 2007). This aggregate prone construct, however, also caused toxicity before beta sheet conformational aggregates were detected using fluorescence, indicating that a pre-fibrillar form of tau aggregate could be toxic (Khlistunova et al. 2006). When expressed in a transgenic mouse line, the aggregate-prone deltaK280 mutant tau repeat domain construct was also more toxic than an anti-aggregate form of deltaK280 tau repeat domain with two proline mutations, although both underwent tau mislocalization to the somatodendritic compartment (Mocanu et al. 2008a). This implicates tau aggregation in neurotoxicity. 
NFT-bearing neurons receive fewer synapses onto their soma assessed by EM in a mouse model of tauopathy (Katsuse et al. 2006), which could contribute to neuronal loss due to deafferentation. Synaptophysin mRNA and other classes of mRNA involved in synaptic signaling and cytoskeletal maintenance are also decreased in NFT-bearing neurons in AD brain (Callahan et al. 1999; Ginsberg et al. 2000), arguing a loss of connectivity of these cells.

\section{New Evidence Suggests Aggregated Tau may not be the Most Toxic Species}

Although NFT formation correlates to some extent with neuronal loss and cognitive decline in $\mathrm{AD}$, there is emerging evidence that the aggregated form of tau may not be the toxic species. One line of evidence supporting this view comes from the studies of dysregulation of axonal transport due to tau alterations. It is known that excessive tau levels can block anterograde transport (Baas and Qiang 2005; Mandelkow et al. 2003; Stoothoff et al. 2009). In reduced microtubule preparations, tau binding to microtubules causes kinesin to detach, thus reducing anterograde transport (Dixit et al. 2008). Thus it is thought that normally, the increasing gradient of tau distally down the axon causes synaptic proteins to detach from microtubules as they reach the synapse, whereas in tauopathy, mislocalization to the soma blocks kinesin binding to the microtubules and prevents it from initiating anterograde transport. This being the case, aggregation of tau in the soma into filaments where it cannot interfere with transport may be beneficial. Tau is also known to stabilize microtubules, and the hyperphosphorylation during disease reduces tau binding to microtubules. Iqbal's group showed that soluble hyper-phosphorylated tau sequesters normal tau, microtubule-associated protein 1 (MAP 1) and MAP 2 in vitro, causing disruption of existing microtubules and inhibition of microtubule assembly (Alonso et al. 1994, 1996; Iqbal et al. 2008). In 2006, this group further demonstrated that sequestering soluble hyperphosphorylated tau into paired helical filaments reduces the binding of hyperphosphorylated tau to normal tau and is a defense mechanism to preserve normal transport (Alonso Adel et al. 2006).

Directly related to axonal transport deficits is regulation of mitochondrial distribution, which is essential in neurons due to high energy demands and extended processes requiring extensive organelle transport (Hollenbeck and Saxton 2005). Several studies in cultured cells, including our own, show that tau overexpression impairs mitochondrial trafficking and distribution, primarily by impairing their anterograde transport (Ebneth et al. 1998; Stamer et al. 2002; Stoothoff et al. 2009). Tau phosphorylation by Cdk5 at position 231 is known to be a prominent change in the $\mathrm{AD}$ brain and has been implicated in mitochondrial clustering (Darios et al. 2005). In the AD brain, Wang et al. (2009) found evidence of impaired balance of mitochondrial fission and fusion. In cultured neurons, they went on to show that similar mitochondrial deficits could be induced with soluble amyloid beta treatment concomitant with synaptic loss. In a more recent study, Zempel et al. (2010) extended this finding to show that oligomeric amyloid beta induced loss of dendritic spines and mitochondrial distribution correlate with mislocalization of tau to dendrites in cultured neurons. In a separate study, caspase-cleaved tau was shown to lead to mitochondrial fragmentation (Quintanilla et al. 2009). All of these studies showing mitochondrial distribution and fission/ fusion deficits link soluble, not fibrillar tau to mitochondrial deficits.

Soluble forms of tau have been found to correlate with neuronal and synaptic dysfunction in several transgenic mouse models (Berger et al. 2007; Hoover et al. 2010; SantaCruz et al. 2005; Sydow et al. 2010). Berger et al. (2007) found a correlation between memory loss in rTg4510 mice and accumulation of SDS-stable oligomeric forms of tau in the soluble (nonNFT) fraction of brain tissue. In two different regulatable mouse models of tauopathy, transgene suppression resulted in recovery of memory deficits despite the continued 
presence of NFT arguing against NFT as the tau species causing synaptic dysfunction (SantaCruz et al. 2005; Sydow et al. 2010). Using the rTg4510 mouse model, Hoover et al. (2010) found deficits in LTP and spatial memory before substantial neuronal loss. In cultured neurons, they found that phosphorylated tau localized to dendritic spines where it impairs synaptic function by decreasing the amounts of synaptic AMPA and NMDA receptors. This study implicates hyperphosphorylated, not aggregated tau in synaptic dysfunction, but NFT do not form in culture so they did not formally address whether NFT also contribute to synaptic dysfunction in vivo. To directly assess whether NFT damage neuronal function, Rocher et al. used slice electrophysiology to record from individual cells with and without NFT in rTg4510 brain. They found that cortical neurons in rTg4510 mice have depolarized resting membrane potential and increased evoked repetitive action potential firing rates and concomitant structural degeneration of dendritic branching and loss of dendritic spines. These functional and structural deficits did not vary between NFT and non-NFT bearing neurons (Rocher et al. 2010), again implicating a soluble form of tau in neuronal dysfunction and degeneration.

In terms of causing cell death, several studies in vitro have shown that nonaggregated forms of tau, including oligomers and caspase-cleaved tau can be toxic (Chung et al. 2001; Lasagna-Reeves et al. 2010). Some familial tau mutations that cause dementia have very little aggregated tau pathology (Reed et al. 2001). Tau expression can also induce neurodegeneration without NFT formation in Drosophila models (Shulman and Feany 2003; Wittmann et al. 2001), indicating toxicity of a soluble form of tau. There is evidence of dissociation of cell death and neurofibrillary pathology from transgenic mouse lines. The rTg4510 mouse model reversibly expresses dementia associated P301L mutant human tau and develops age-related NFT and neuronal loss (SantaCruz et al. 2005; Spires et al. 2006). In this model, the CA1 region of the hippocampus undergoes both severe neuronal loss and extensive NFT formation, however, most of the dentate gyrus granule cells die despite a lack of NFT and the striatum has significant NFT formation without much neuronal loss, indicating some dissociation between regions with NFT formation and neuronal loss (Fig. 1). Further, transgene suppression can prevent neuronal loss without affecting NFTs in rTg4510 mice (Spires et al. 2006). In aggregate-prone tau repeat domain transgenic mice, transgene suppression from 10 to 14 months reversed memory loss and LTP deficits without removing most of the neurofibrillary pathology, indicating the presence of the proaggregating tau protein but not the aggregates themselves contribute to dysfunction (Sydow et al. 2010). Neuronal loss was not formally quantified in this study, but further neuronal loss after transgene suppression may have also been prevented as seen in the rTg4510 model.

\section{In Vivo Imaging Directly Addresses Whether Tangles Cause Cell Death}

To directly observe NFT formation in the intact brain and whether this aggregation leads to cell death, we developed a method using in vivo multiphoton imaging in the rTg4510 transgenic model of tauopathy. Multiphoton imaging through a craniotomy sealed with a glass coverslip allows penetration of laser excitation deep into the neocortex, including layers II-III which form NFT in the rTg4510 mice (Spires-Jones et al. 2011). This technique requires introduction of a fluorophore to bind the structure of interest. In the case of NFT, we first used thioflavin $\mathrm{S}$ (ThioS), which is known to bind amyloid fibrils including NFT. In rTg4510 mice and mice injected with AAV encoding human tau, ThioS binding to NFT occurs after mislocalization of tau to the soma and hyper-phosphorylation assessed using tau and phospho-tau immunochemistry (de Calignon et al. 2010; Spires-Jones et al. 2008). ThioS binding is also a later event than silver-positive staining of NFT, the classic marker for a mature tangle, thus the staining we observe in vivo with ThioS represents true NFT pathology. Topical application of ThioS $(0.025 \%$ in sterile PBS) to the cortex after removing 
the meninges labels NFT in the living brain (de Calignon et al. 2010;Spires-Jones et al. 2008). ThioS does not cross the blood-brain barrier when administered systemically, and topical application can only be performed at the time of cranial window implantation, so we also developed the use of FSB and X-34, blood-brain barrier penetrating compounds first used by Goedert's group to label NFT in mouse models (Velasco et al. 2008), to image NFT after i.v. injection and observe similar clear labeling of NFT throughout the brain (de Calignon et al. 2010). The use of these systemically administered dyes allows longitudinal imaging of NFT to follow whether cells disappear after tangle formation. It is worth noting that the appearance of ThioS or X-34 positive NFT is preceded by tau mislocalization, phosphorylation, and misfolding that cannot be detected by amyloid binding dyes in vivo but is readily observed postmortem with immunohistochemistry. Thus, we observe the last step of mature tangle formation in vivo, likely after a critical number of filaments form in a discrete cellular compartment allowing visualization with these dyes with 2-photon microscopy.

Furthermore, we developed the use of fluorescent indicators of caspase activation in vivo to test the hypothesis that the observed cell death in rTg4510 mice is a caspase-mediated phenomenon. Using a combination of ThioS and a polycaspase indicator (red fluorescent inhibitor of capases from Invitrogen), we observed that a subset of tangle-bearing neurons contain active caspases and very rare non tangle-bearing neurons also show caspase activation in these mice (Fig. 2). Surprisingly, caspase activation appears before NFT formation when neurons contain soluble tau mislocalized to the soma. Neurons with active caspases rapidly form NFT, over the course of hours, then these NFT bearing neurons persist for days. Caspases ultimately must be deactivated in these cells since all newly formed NFT have active caspases and only 5\% of total NFT are positive for caspase activation. Using Hoescht labeling, we confirmed that neuronal nuclei appear healthy and intact the day after a new tangle forms (de Calignon et al. 2010). Postmortem, we have found that rTg4510 mice do not develop "ghost" tangles, which has been confirmed with electron microscopy in this model (Ludvigson et al. 2010), so the NFT that we follow for several days in vivo are highly likelytobeliveneurons.

These in vivo data show that tangles form very rapidly downstream of caspase activation and that these tangles do not cause the cell to die acutely, in fact, caspase activation is reversed and cells live for at least 5 days. Based on these experiments, we postulate that aggregated tau may not cause acute cell death but may in fact either be neutral or protect the neuron in the short term from the toxic effects of soluble species of tau. This conclusion is supported by transgene suppression data showing that lowering levels of soluble tau prevents further neuronal loss in the face of continued presence and accumulation of NFT (Spires et al. 2006). Future essential questions remain including which neurons are dying in tauopathies. Tangle bearing neurons do not die acutely in the rTg 4510 model, but does the aggregate eventually cause impaired transport, protein degradation system breakdown, and slow death? Longitudinal imaging of NFT with systemic administration of X-34 will allow NFT to be followed long term, potentially throughout the lifetime of the animal, to definitively address the question of whether tangle-bearing neurons eventually die. Or do neurons with mislocalized, hyperphosphorylated, soluble tau that do not seed a tangle to sequester toxic soluble species die? It is also important to elucidate the mechanisms of cell death to develop therapeutic interventions.

\section{Acknowledgments}

This work was supported by National Institute of Health grants AG08487, T32AG000278, AG026249, K99AG33670 and the Alzheimer's Association Zenith Award. 


\section{References}

Allen B, Ingram E, Takao M, Smith MJ, Jakes R, Virdee K, Yoshida H, Holzer M, Craxton M, Emson PC, Atzori C, Migheli A, Crowther RA, Ghetti B, Spillantini MG, Goedert M. Abundant tau filaments and nonapoptotic neurodegeneration in transgenic mice expressing human P301S tau protein. J Neurosci. 2002; 22:9340-93515. [PubMed: 12417659]

Alonso, Adel C.; Li, B.; Grundke-Iqbal, I.; Iqbal, K. Polymerization of hyperphosphorylated tau into filaments eliminates its inhibitory activity. Proc Natl Acad Sci USA. 2006; 103:8864-8869. [PubMed: 16735465]

Alonso AC, Zaidi T, Grundke-Iqbal I, Iqbal K. Role of abnormally phosphorylated tau in the breakdown of microtubules in Alzheimer disease. Proc Natl Acad Sci USA. 1994; 91:5562-5566. [PubMed: 8202528]

Alonso AC, Grundke-Iqbal I, Iqbal K. Alzheimer's disease hyperphosphorylated tau sequesters normal tau into tangles of filaments and disassembles microtubules. Nat Med. 1996; 2:783-787. [PubMed: 8673924]

Alzheimer A. Ubereine eigenartige Erkrankung der Hirnrinde. Allgemeine Zeitschrift fur Psychiatr Psych-Gericht Med. 1907; 64:146-148.

Andorfer C, Acker CM, Kress Y, Hof PR, Duff K, Davies P. Cell-cycle reentry and cell death in transgenic mice expressing nonmutant human tau isoforms. J Neurosci. 2005; 25:5446-5454. [PubMed: 15930395]

Arriagada PV, Growdon JH, Hedley-Whyte ET, Hyman BT. Neurofibrillary tangles but not senile plaques parallel duration and severity of Alzheimer's disease. Neurology. 1992; 42:631-639. [PubMed: 1549228]

Baas PW, Qiang L. Neuronal microtubules: when the MAP is the roadblock. Trends Cell Biol. 2005; 15:183-187. [PubMed: 15817373]

Berger Z, Roder H, Hanna A, Carlson A, Rangachari V, Yue M, Wszolek Z, Ashe K, Knight J, Dickson D, Andorfer C, Rosenberry TL, Lewis J, Hutton M, Janus C. Accumulation of pathological tau species and memory loss in a conditional model of tauopathy. J Neurosci. 2007; 27:3650-3662. [PubMed: 17409229]

Braak H, Braak E. Diagnostic criteria for neuropathologic assessment of Alzheimer's disease. Neurobiol Aging. 1997; 18:S85-S88. [PubMed: 9330992]

Bramblett GT, Goedert M, Jakes R, Merrick SE, Trojanowski JQ, Lee VM. Abnormal tau phosphorylation at Ser396 in Alzheimer's disease recapitulates development and contributes to reduced microtubule binding. Neuron. 1993; 10:1089-1099. [PubMed: 8318230]

Bretteville A, Planel E. Tau aggregates: toxic, inert, or protective species? J Alzheimers Dis. 2008; 14:431-436. [PubMed: 18688094]

Bulic B, Pickhardt M, Khlistunova I, Biernat J, Mandelkow EM, Mandelkow E, Waldmann H. Rhodanine-based tau aggregation inhibitors in cell models of tauopathy. Angew Chem Int Ed Engl. 2007; 46:9215-9219. [PubMed: 17985339]

Callahan LM, Vaules WA, Coleman PD. Quantitative decrease in synaptophysin message expression and increase in cathepsin D message expression in Alzheimer disease neurons containing neurofibrillary tangles. J Neuropathol Exp Neurol. 1999; 58:275-287. [PubMed: 10197819]

Chung CW, Song YH, Kim IK, Yoon WJ, Ryu BR, Jo DG, Woo HN, Kwon YK, Kim HH, Gwag BJ, Mook-Jung IH, Jung YK. Proapoptotic effects of tau cleavage product generated by caspase-3. Neurobiol Dis. 2001; 8:162-172. [PubMed: 11162250]

Congdon EE, Duff KE. Is tau aggregation toxic or protective? J Alzheimers Dis. 2008; 14:453-457. [PubMed: 18688098]

Darios F, Muriel MP, Khondiker ME, Brice A, Ruberg M. Neurotoxic calcium transfer from endoplasmic reticulum to mitochondria is regulated by cyclin-dependent kinase 5-dependent phosphorylation of tau. J Neurosci. 2005; 25:4159-4168. [PubMed: 15843619]

de Calignon A, Fox LM, Pitstick R, Carlson GA, Bacskai BJ, Spires-Jones TL, Hyman BT. Caspase activation precedes and leads to tangles. Nature. 2010; 464:1201-1204. [PubMed: 20357768]

Dixit R, Ross JL, Goldman YE, Holzbaur EL. Differential regulation of dynein and kinesin motor proteins by tau. Science. 2008; 319:1086-1089. [PubMed: 18202255] 
Ebneth A, Godemann R, Stamer K, Illenberger S, Trinczek B, Mandelkow E. Overexpression of tau protein inhibits kinesin-dependent trafficking of vesicles, mitochondria, and endoplasmic reticulum: implications for Alzheimer's disease. J Cell Biol. 1998; 143:777-794. [PubMed: 9813097]

Giannakopoulos P, Herrmann FR, Bussiere T, Bouras C, Kovari E, Perl DP, Morrison JH, Gold G, Hof PR. Tangle and neuron numbers, but not amyloid load, predict cognitive status in Alzheimer's disease. Neurology. 2003; 60:1495-1500. [PubMed: 12743238]

Ginsberg SD, Hemby SE, Lee VM, Eberwine JH, Trojanowski JQ. Expression profile of transcripts in Alzheimer's disease tangle-bearing CA1 neurons. Ann Neurol. 2000; 48:77-87. [PubMed: 10894219]

Goedert M, Spillantini MG. A century of Alzheimer's disease. Science. 2006; 314:777-781. [PubMed: 17082447]

Goedert M, Wischik CM, Crowther RA, Walker JE, Klug A. Cloning and sequencing of the cDNA encoding a core protein of the paired helical filament of Alzheimer disease: identification as the microtubule-associated protein tau. Proc Natl Acad Sci USA. 1988; 85:4051-4055. [PubMed: 3131773]

Gomez-Isla T, Price JL, McKeel DW Jr, Morris JC, Growdon JH, Hyman BT. Profound loss of layer II entorhinal cortex neurons occurs in very mild Alzheimer's disease. J Neurosci. 1996; 16:44914500. [PubMed: 8699259]

Gomez-Isla T, Hollister R, West H, Mui S, Growdon JH, Petersen RC, Parisi JE, Hyman BT. Neuronal loss correlates with but exceeds neurofibrillary tangles in Alzheimer's disease. Ann Neurol. 1997; 41:17-24. [PubMed: 9005861]

Hollenbeck PJ, Saxton WM. The axonal transport of mitochondria. J Cell Sci. 2005; 118:5411-5419. [PubMed: 16306220]

Hoover BR, Reed MN, Su J, Penrod RD, Kotilinek LA, Grant MK, Pitstick R, Carlson GA, Lanier LM, Yuan L-L, Ashe KH, Liao D. Tau mislocalization to dendritic spines mediates synaptic dysfunction independently of neurodegeneration. Neuron. 2010; 68:1067-1081. [PubMed: 21172610]

Hutton M. Missense and splice site mutations in tau associated with FTDP-17: multiple pathogenic mechanisms. Neurology. 2001; 56:21S-25S.

Hutton M, Lendon CL, Rizzu P, Baker M, Froelich S, Houlden H, Pickering-Brown S, Chakraverty S, Isaacs A, Grover A, Hackett J, Adamson J, Lincoln S, Dickson D, Davies P, Petersen RC, Stevens M, de Graaff E, Wauters E, van Baren J, Hillebrand M, Joosse M, Kwon JM, Nowotny P, Che LK, Norton J, Morris JC, Reed LA, Trojanowski JQ, Basun H, Lannfelt L, Neystat M, Fahn S, Dark F, Tannenberg T, Dodd PR, Hayward N, Kwok JB, Schofield PR, Andreadis A, Snowden JS, Craufurd D, Neary D, Owen F, Oostra BA, Hardy J, Goate A, Van Swieten JC, Mann DM, Lynch T, Heutink P. Association of missense and 5'-splice-site mutations in tau with the inherited dementia FTDP-17. Nature. 1998; 393:702-705. [PubMed: 9641683]

Hutton M, Lewis J, Dickson D, Yen SH, McGowan E. Analysis of tauopathies with transgenic mice. Trends Mol Med. 2001; 7:467-470. [PubMed: 11597522]

Hyman BT, Augustinack JC, Ingelsson M. Transcriptional and conformational changes of the tau molecule in Alzheimer's disease. Biochim Biophys Acta. 2005; 1739:150-157. [PubMed: 15615634]

Iqbal K, Alonso Adel C, Grundke-Iqbal I. Cytosolic abnormally hyperphosphorylated tau but not paired helical filaments sequester normal MAPs and inhibit microtubule assembly. J Alzheimers Dis. 2008; 14:365-370. [PubMed: 18688085]

Katsuse O, Lin WL, Lewis J, Hutton ML, Dickson DW. Neurofibrillary tangle-related synaptic alterations of spinal motor neurons of P301L tau transgenic mice. Neurosci Lett. 2006; 409:95-99. [PubMed: 17010516]

Khlistunova I, Biernat J, Wang Y, Pickhardt M, von Bergen M, Gazova Z, Mandelkow E, Mandelkow EM. Inducible expression of Tau repeat domain in cell models of tauopathy: aggregation is toxic to cells but can be reversed by inhibitor drugs. J Biol Chem. 2006; 281:1205-1214. [PubMed: 16246844] 
Kuret J, Congdon EE, Li G, Yin H, Yu X, Zhong Q. Evaluating triggers and enhancers of tau fibrillization. Microsc Res Technol. 2005; 67:141-155.

Lasagna-Reeves CA, Castillo-Carranza DL, Guerrero-Muoz MJ, Jackson GR, Kayed R. Preparation and characterization of neurotoxic tau oligomers. Biochemistry. 2010; 49:10039-10041. [PubMed: 21047142]

Ludvigson AE, Luebke JI, Lewis J, Peters A. Structural abnormalities in the cortex of the rTg4510 mouse model of tauopathy: a light and electron microscopy study. Brain Struct Funct. 2010; 216:31-42. [PubMed: 21152933]

Mandelkow EM, Stamer K, Vogel R, Thies E, Mandelkow E. Clogging of axons by tau, inhibition of axonal traffic and starvation of synapses. Neurobiol Aging. 2003; 24:1079-1085. [PubMed: 14643379]

Mocanu M-M, Nissen A, Eckermann K, Khlistunova I, Biernat J, Drexler D, Petrova O, Schonig K, Bujard H, Mandelkow E, Zhou L, Rune G, Mandelkow E-M. The potential for - structure in the repeat domain of tau protein determines aggregation, synaptic decay, neuronal loss, and coassembly with endogenous tau in inducible mouse models of tauopathy. J Neurosci. 2008a; 28:737-748. [PubMed: 18199773]

Mocanu MM, Nissen A, Eckermann K, Khlistunova I, Biernat J, Drexler D, Petrova O, Schonig K, Bujard H, Mandelkow E, Zhou L, Rune G, Mandelkow EM. The potential for beta-structure in the repeat domain of tau protein determines aggregation, synaptic decay, neuronal loss, and coassembly with endogenous Tau in inducible mouse models of tauopathy. J Neurosci. 2008b; 28:737-748. [PubMed: 18199773]

Quintanilla RA, Matthews-Roberson TA, Dolan PJ, Johnson GV. Caspase-cleaved tau expression induces mitochondrial dysfunction in immortalized cortical neurons: implications for the pathogenesis of Alzheimer disease. J Biol Chem. 2009; 284:18754-18766. [PubMed: 19389700]

Reed LA, Wszolek ZK, Hutton M. Phenotypic correlations in FTDP-17. Neurobiol Aging. 2001; 22:89-107. [PubMed: 11164280]

Rocher AB, Crimins JL, Amatrudo JM, Kinson MS, Todd-Brown MA, Lewis J, Luebke JI. Structural and functional changes in tau mutant mice neurons are not linked to the presence of NFTs. Exp Neurol. 2010; 223:385-393. [PubMed: 19665462]

SantaCruz K, Lewis J, Spires T, Paulson J, Kotilinek L, Ingelsson M, Guimaraes A, DeTure M, Ramsden M, McGowan E, Forster C, Yue M, Orne J, Janus C, Mariash A, Kuskowski M, Hyman $\mathrm{B}$, Hutton M, Ashe KH. Tau suppression in a neurodegenerative mouse model improves memory function. Science. 2005; 309:476-481. [PubMed: 16020737]

Selkoe DJ. Alzheimer's disease: genes, proteins, and therapy. Physiol Rev. 2001; 81:741-766. [PubMed: 11274343]

Shulman JM, Feany MB. Genetic modifiers of tauopathy in drosophila. Genetics. 2003; 165:12331242. [PubMed: 14668378]

Spires TL, Hyman BT. Transgenic models of Alzheimer's disease: learning from animals. NeuroRx. 2005; 2:423-437. [PubMed: 16389306]

Spires TL, Orne JD, SantaCruz K, Pitstick R, Carlson GA, Ashe KH, Hyman BT. Region-specific dissociation of neuronal loss and neurofibrillary pathology in a mouse model of tauopathy. Am $\mathrm{J}$ Pathol. 2006; 168:1598-1607. [PubMed: 16651626]

Spires-Jones TL, de Calignon A, Matsui T, Zehr C, Pitstick R, Wu HY, Osetek JD, Jones PB, Bacskai BJ, Feany MB, Carlson GA, Ashe KH, Lewis J, Hyman BT. In vivo imaging reveals dissociation between caspase activation and acute neuronal death in tangle-bearing neurons. J Neurosci. 2008; 28:862-867. [PubMed: 18216194]

Spires-Jones TL, Stoothoff WH, de Calignon A, Jones PB, Hyman BT. Tau pathophysiology in neurodegeneration: a tangled issue. Trends Neurosci. 2009; 32:150-159. [PubMed: 19162340]

Spires-Jones TL, de Calignon A, Meyer-Luehmann M, Bacskai BJ, Hyman BT. Monitoring protein aggregation and toxicity in Alzheimer's disease mouse models using in vivo imaging. Methods. 2011; 53:201-207. [PubMed: 21163350]

Stamer K, Vogel R, Thies E, Mandelkow E, Mandelkow EM. Tau blocks traffic of organelles, neurofilaments, and APP vesicles in neurons and enhances oxidative stress. J Cell Biol. 2002; 156:1051-1063. [PubMed: 11901170] 
Stoothoff WH, Johnson GV. Tau phosphorylation: physiological and pathological consequences. Biochim Biophys Acta. 2005; 1739:280-297. [PubMed: 15615646]

Stoothoff W, Jones PB, Spires-Jones TL, Joyner D, Chhabra E, Bercury K, Fan Z, Xie H, Bacskai B, Edd J, Irimia D, Hyman BT. Differential effect of three-repeat and four-repeat tau on mitochondrial axonal transport. J Neurochem. 2009; 111:417-427. [PubMed: 19686388]

Sydow A, Van der Jeugd A, Zheng F, Ahmed T, Balschun D, Petrova O, Drexler D, Zhou L, Rune G, Mandelkow E, D'Hooge R, Alzheimer C, Mandelkow EM. Tau-induced defects in synaptic plasticity, learning, and memory are reversible in transgenic mice after switching off the toxic Tau mutant. J Neurosci. 2010; 31:2511-2525. [PubMed: 21325519]

Terry RD. Do neuronal inclusions kill the cell? J Neural Transm Suppl. 2000; 59:91-93. [PubMed: 10961422]

van de Nes JA, Nafe R, Schlote W. Non-tau based neuronal degeneration in Alzheimer's disease ... an immunocytochemical and quantitative study in the supragranular layers of the middle temporal neocortex. Brain Res. 2008; 1213:152-165. [PubMed: 18455153]

Velasco A, Fraser G, Delobel P, Ghetti B, Lavenir I, Goedert M. Detection of filamentous tau inclusions by the fluorescent Congo red derivative FSB [(trans, trans)-1-fluoro-2,5-bis(3hydroxycarbonyl-4-hydroxy)styrylbenzene]. FEBS Lett. 2008; 582:901-906. [PubMed: 18291106]

Vogt BA, Vogt LJ, Vrana KE, Gioia L, Meadows RS, Challa VR, Hof PR, Van Hoesen GW. Multivariate analysis of laminar patterns of neurodegeneration in posterior cingulate cortex in Alzheimer's disease. Exp Neurol. 1998; 153:8-22. [PubMed: 9743563]

Wang YP, Biernat J, Pickhardt M, Mandelkow E, Mandelkow EM. Stepwise proteolysis liberates tau fragments that nucleate the Alzheimer-like aggregation of full-length tau in a neuronal cell model. Proc Natl Acad Sci USA. 2007; 104:10252-10257. [PubMed: 17535890]

Wang X, Su B, Lee HG, Li X, Perry G, Smith MA, Zhu X. Impaired balance of mitochondrial fission and fusion in Alzheimer's disease. J Neurosci. 2009; 29:9090-9103. [PubMed: 19605646]

Wittmann CW, Wszolek MF, Shulman JM, Salvaterra PM, Lewis J, Hutton M, Feany MB. Tauopathy in drosophila: neuro-degeneration without neurofibrillary tangles. Science. 2001; 293:711-714. [PubMed: 11408621]

Zehr C, Lewis J, McGowan E, Crook J, Lin WL, Godwin K, Knight J, Dickson DW, Hutton M. Apoptosis in oligodendrocytes is associated with axonal degeneration in P301L tau mice. Neurobiol Dis. 2004; 15:553-562. [PubMed: 15056463]

Zempel H, Thies E, Mandelkow E, Mandelkow E-M. A \{beta\} Oligomers cause localized $\mathrm{Ca}^{2+}$ elevation, missorting of endogenous tau into dendrites, tau phosphorylation, and destruction of microtubules and spines. J Neurosci. 2010; 30:11938-11950. [PubMed: 20826658] 


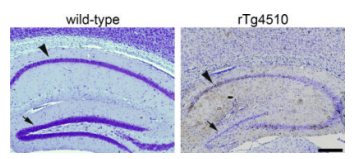

Fig. 1.

Some dissociation between NFT (brown) and neuronal loss (nuclei labeled blue with cresyl violet) is observed in rTg4510 mice which have substantial neuronal loss in dentate gyrus (arrows) despite very few NFT. CA1 (arrowheads) undergoes both NFT formation and neuronal loss. Scale: $500 \mu \mathrm{m}$ 


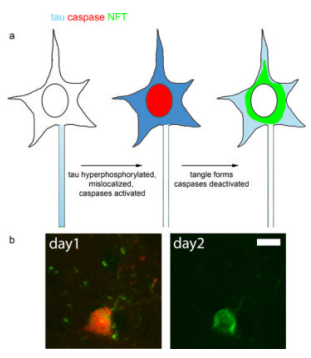

Fig. 2.

Caspase activation precedes NFT formation in rTg4510 mice as modeled ion (a). Tau becomes hyperphosphorylated and mislocalized to the somatodendritic compartment. Caspases are then activated and NFT form very rapidly. Since neurons with new NFT survive at least 5 days and caspases are turned off, we postulate that NFT formation reduces the toxic soluble hyperphosphorylated tau levels in the soma allowing caspases to become deactivated preventing apoptosis. An example of caspase activation in vivo followed $24 \mathrm{~h}$ later by a Thioflavin S positive tangle is shown in (b). Scale: $10 \mu \mathrm{m}$ 